\title{
A Quantitative and Qualitative High Performance Liquid Chromatographic Determination of Aceclofenac Specified Impurity-B (Methyl[2-[(2, 6-dichlorophenyl)amino] phenyl]acetate) in Aceclofenac Bulk Drug
}

\author{
SOMASHEKAR P.L a $^{\mathrm{a}^{*}}$, SANJAY PAI P.N ${ }^{\mathrm{b}}$ and GOPALKRISHNA RAO ${ }^{\mathrm{b}}$ \\ ${ }^{\mathrm{a} D e p a r t m e n t ~ o f ~ Q u a l i t y ~ A s s u r a n c e, ~ A l-A m e e n ~ C o l l e g e ~ o f ~ P h a r m a c y, ~}$ \\ Near Lalbagh Main Gate, Hosur Road, Bangalore -560027, India \\ ${ }^{b}$ Department of Pharmaceutical Chemistry, Goa College of Pharmacy, \\ $18^{\text {th }}$ June Road, Panaji, Goa- 403001, India \\ somashekarpl@gmail.com
}

Received 8 March 2013 / Accepted 30 April 2013

\begin{abstract}
Aceclofenac is a phenylacetic acid derivative with potent analgesic and anti-inflammatory properties and an improved gastro-intestinal tolerance. In the present study, a reversed-phase HPLC method was developed for analysis of aceclofenac and applied for detection and quantification of aceclofenac specified impurity-B (methyl[2-[(2, 6-dichlorophenyl)amino]phenyl]acetate) with UV detection in bulk drug. Aceclofenac and its impurity were separated using an acetonitrile-phosphate buffer (60:40) isocratic method with a flow rate of $1 \mathrm{~mL} / \mathrm{min}$ and $\mathrm{UV}$ detection at $275 \mathrm{~nm}$. The retention times for aceclofenac and its impurity were $3.0 \mathrm{~min}$ and $13.04 \mathrm{~min}$ respectively. The method was validated as per ICH guidelines. The calibration was linear over the range of $1-25 \mathrm{mcg} / \mathrm{mL}$ for aceclofenac and 1-20 mcg/mL for Aceclofenac impurity-B. The method showed excellent sensitivity (detection limit of $10 \mathrm{ng} / \mathrm{mL}$ ) with good precision and accuracy. This sensitive and selective method can be used for detection and quantification of aceclofenac impurity-B in aceclofenac bulk drug in order to control and regulate process related impurity.
\end{abstract}

Keywords: Aceclofenac, Aceclofenac impurity, HPLC method

\section{Introduction}

Aceclofenac [(2, 6-dichlorophenylamino) phenyl]acectoxyacetic acid is a phenyl acetic acid derivative that shows analgesic properties and good tolerability profile in a variety of painful conditions $^{1-3}$. Aceclofenac inhibits the cyclooxygenase enzyme and thus exerts its antiinflammatory activity by inhibition of prostaglandin synthesis. It is used in the treatment of rheumatic disorders and soft tissue injuries. The European pharmacopoeia supplement 2000 and the British pharmacopoeia reported HPLC methods for the determination of aceclofenac in presence of diclofenac ${ }^{1,2}$. 
<smiles>O=C(O)COC(=O)Cc1ccccc1Nc1c(Cl)cccc1Cl</smiles>

Figure 1. Aceclofenac: [(2, 6-dichlorophenylamino)phenyl]acectoxyacetic acid<smiles>COC(=O)Cc1ccccc1Nc1c(Cl)cccc1Cl</smiles>

Figure 2. Aceclofenac impurity-B (methyl [2-[(2, 6-dichlorophenyl)amino]phenyl]acetate)

The safety of a drug product is dependent not only on the toxicological properties of the active drug substance, but also on the toxicological properties of its impurities ${ }^{4}$. Thus, there is an ever-increasing interest in impurities present in APIs. The different Pharmacopoeias, such as the European Pharmacopoeia (Ph.Eur.), United States Pharmacopeia (USP) and International Pharmacopoeia (Ph.Int.) are incorporating specification limits to acceptable levels of impurities present in the active pharmaceutical ingredients (API's) or finished pharmaceutical products (FPPs) formulations, based upon found levels in approved market samples ${ }^{5-8}$.

Regulatory requirements for the identification, qualification, and control of impurities in drug substances and their formulated products are now being explicitly defined, particularly through the International Conference on Harmonization (ICH). It is also recommended by ICH that all routine impurities at or above $0.1 \%$ level, should be identified through appropriate analytical methods ${ }^{9,10}$. Aceclofenac is cited in the British Pharmacopoeia to have contamination by many impurities and one among of those impurities was found ${ }^{1}$ impurity-B. Therefore, it was thought worth determining and quantifying the impurities of aclofenac to ensure the quality, efficacy and safety of drug.

Numerous analytical methods for the determination of aceclofenac in bulk drug as well as in formulations have been reported in literature viz. UV-spectrophotometry ${ }^{11}$, colorimertic method $^{12}$ densitometric ${ }^{13}$, HPLC ${ }^{14-16}$, HPLC method developed for estimation of aceclofenac and its three metabolite in human plasm $^{17}$, RP-HPLC ${ }^{18,19}$ and stripping Voltametric method $^{20}$, LC-MS $^{21}$, capillary electrophoresis ${ }^{22}$ and simultaneous HPLC-UV determination of rhein and aceclofenac in human plasma ${ }^{23}$.

From preceding details of relevant literature it was apparent that a validated method is required to be developed which would be capable for simultaneous determination of aceclofenac in the presence of its reported impurities. Thus, the aim of current study was to develop and validate an RP-HPLC method for the identification and determination of aceclofenac and its known impurity-B in drug component in accordance with the $\mathrm{ICH}^{24}$ guidance document.

\section{Experimental}

A qualified standard of Aceclofenac was gifted by Karnataka Antibiotics and Pharmaceuticals Ltd (Bangalore, India). Impurity-B was synthesized and spectral confirmation was carried out in Department of Quality Assurance, Al-Ameen College of Pharmacy, Bangalore. Analytical/HPLC grade chemicals and solvents used were obtained from Ranbaxy Fine Chemicals Limited (Delhi, India).

\section{Chromatographic conditions}

HPLC-UV investigation of the estimation was performed on a High Performance Liquid Chromatography 10AT Shimadzu-SPD10A detector, Rheodyne $100 \mu \mathrm{L}$ injector. 
The chromatographic conditions were optimized by different means (using different buffers and different organic phases). Early chromatographic work was performed GraceSmart $\mathrm{RP}^{-\mathrm{C}_{18}}, 250 \mathrm{~mm} \times 4.6 \mathrm{~mm}, 5 \mu \mathrm{m}$ columns as stationary phase and various combinations of buffered ( $\mathrm{pH} 4.5-5.0)$ organic phases (ACN and /or methanol). The flow rate of mobile phase was varied within $0.5-1.5 \mathrm{~mL} / \mathrm{min}$. Wavelength for monitoring the eluent was selected by scanning standard solution of acelofenac and impurity within 200-400 nm using double beam UV-Visible spectrophotometer (Shimadzu1800, Japan). All noted measurements were performed with an injection volume of $100 \mu \mathrm{L}, 1 \mathrm{~mL} / \mathrm{min}$ flow rate and $\mathrm{UV}$ detection at $275 \mathrm{~nm}$ using mobile phase- acetonitrile and phosphate buffer pH-5 (60:40).

\section{Preparation of solutions}

\section{Preparation of mobile phase}

$10 \mathrm{mM}$ of potassium dihydrogen orthophosphate buffer $\left(\mathrm{KH}_{2} \mathrm{PO}_{4}\right) \mathrm{pH} 5$ was prepared by taking $1.36 \mathrm{~g}$ of potassium dihydrogen orthophosphate $\left(\mathrm{KH}_{2} \mathrm{PO}_{4}\right)$ in $1000 \mathrm{~mL}$ of water. The $\mathrm{pH}$ was adjusted to 5 using orthophosphoric acid. The mobile phase was prepared in the ratio of 60:40 (Acetonitrile: $10 \mathrm{mM}$ Potassium dihydrogen orthophosphate buffer) filtered with nylon membrane filter of $0.22 \mu$, degassed and sonicated for $10 \mathrm{~min}$.

\section{Standard stock solutions}

Standard stock solution aceclofenac and aceclofenac impurity-B (1 mg/mL each) were individually prepared by dissolving $10 \mathrm{mg}$ each in the mobile phase separately in $10 \mathrm{~mL}$ volumetric flasks. The volumes of $1 \mathrm{~mL}$ of above solutions were diluted to $10 \mathrm{~mL}$ with mobile phase separately in volumetric flasks $(100 \mu \mathrm{g} / \mathrm{mL}$ each $)$.

\section{Preparation of resolution mixture solution}

$0.5 \mathrm{~mL}$ of each standard stock solution aceclofenac and aceclofenac impurity-B were diluted $10 \mathrm{~mL}$ with mobile phase in a $10 \mathrm{~mL}$ volumetric flask $(5 \mu \mathrm{g} / \mathrm{mL}$ each). This solution was filtered through a $0.45 \mathrm{~mm}$ nylon 66-membrane filter and used for the analysis.

\section{System suitability}

System suitability parameters were evaluated to verify that the analytical system is working properly and can give accurate and precise results. Parameters such as peak asymmetry factor, tailing factor, resolution between aceclofenac and impurity-B and \%RSD of theoretical area obtained from resolution mixture solutions of aceclofenac and impurity-B (in triplicate), were evaluated.

\section{Analytical method validation}

\section{Linearity}

Linearity test for the method was performed according to the guidelines laid by ICH. Appropriate aliquots of aceclofenac stock solution were spiked with appropriate volumes of stock solutions of known impurity-B and diluted with the diluent to get solutions containing required concentrations.

Calibration curve was drawn by plotting the peak areas of aceclofenac and impurity-B versus its corresponding concentration. Values of coefficient of regression, slope, $Y$-intercept and percentage curve fitting of the calibration curve were calculated.

\section{Limit of detection (LOD)}

Lowest amount of analyte in a sample that can be detected but not necessarily quantitified as an exact value, under the stated experimental conditions. In instrumental methods of 
determination, limit of detection is generally determined by the analysis of samples with known concentrations of analyte and by establishing the minimum level at which the analyte can be reliably detected. Diluted standard solution mixture of aceclofenac and aceclofenac impurity $-\mathrm{B}$ volumes of $1.0 \mathrm{~mL}-0.1 \mathrm{~mL}$ were pipetted into ten different $10 \mathrm{~mL}$ volumetric flasks. The volume was made up with the mobile phase to get the concentration of $1-0.1 \mu \mathrm{g} / \mathrm{mL}$.

\section{Precision}

The precision of method and system was determined by replicate injection of standard solution and \%RSD was calculated for the results.

\section{Method precision (Repeatability)}

Six solutions containing aceclofenac $(5 \mu \mathrm{g} / \mathrm{mL})$ were spiked with aceclofenac impurity-B $(5 \mu \mathrm{g} / \mathrm{mL})$ solutions were injected. Chromatography was performed and \%RSD were calculated for the concentrations of aceclofenac and impurity-B in replicates.

\section{System precision}

Six solutions containing aceclofenac $(5 \mu \mathrm{g} / \mathrm{mL})$ were spiked with aceclofenac impurity-B (5 $\mu \mathrm{g} / \mathrm{mL}$ ) solutions were injected. Chromatography was performed and \%RSD were calculated for the peak areas of replicates aceclofenac and impurity-B in replicates.

\section{Intermediate precision}

Intermediate precision expresses within-laboratories variations like different days, different analysts and different equipment.

\section{Inter-day precision}

Six solutions containing aceclofenac $(5 \mu \mathrm{g} / \mathrm{mL})$ were spiked with aceclofenac impurity-B $(5 \mu \mathrm{g} / \mathrm{mL})$ solutions were injected separately on different days and chromatograms recorded. The $\%$ RSD were calculated for concentrations of aceclofenac and impurity-B in replicates.

\section{Intra-day precision}

Six solutions containing aceclofenac $(5 \mu \mathrm{g} / \mathrm{mL})$ were spiked with aceclofenac impurity-B $(5 \mu \mathrm{g} / \mathrm{mL})$ solutions were injected separately at different intervals on the same day and chromatograms recorded. The \%RSD was calculated for concentrations of aceclofenac and impurity-B in replicates.

\section{Accuracy}

Recovery studies were performed in triplicate at different concentration levels by spiking the standard aceclofenac drug and impurity-B at three levels $80 \%, 100 \%$ and $120 \%$ to evaluate the accuracy of the proposed method. Solutions for the purpose were prepared by standard addition of aceclofenac stock solution to laboratory mixture solution.

\section{Specificity}

Specificity is the ability of the method to measure the analyte response in the presence of its potential impurities and degradation products. In specificity separation, resolutions were observed between aceclofenac standard solution, placebo solution and its impurity-B.

\section{Ruggedness}

The estimation was performed by two different analysts. Successive six injections working standard solution of aceclofenac and aceclofenac impurity-B concentration $5 \mu \mathrm{g} / \mathrm{mL}$ were injected by each analyst and chromatograms were recorded. The \% RSD was calculated from the peak areas of replicates. 


\section{Robustness}

The method was performed with little variations like changing the $\mathrm{pH}$ ( \pm 0.2 unit) of mobile phase, changing the mobile phase flow rate $( \pm 0.1 \mathrm{~mL} / \mathrm{min})$ and changing absorption maxima wavelength ( \pm 2 unit). Chromatograms of six replicas of laboratory mixture solution of aceclofenac and aceclofenac impurity-B were obtained and effect of each deliberate change was evaluated by applying system suitability parameters. The value of \%RSD was calculated for each deliberate change.

\section{Results and Discussion}

A new method was developed for quantification of aceclofenac and known aceclofenac impurity-B synthesized in the laboratory. The synthesized impurity-B was characterized with spectral studies have been used as a reference standard for estimation of impurity. The developed method involved isocratic elution containing mobile phase system of acetonitrile: Phosphate buffer $\mathrm{pH} 5$ in the ratio of 60:40 with flow rate of $1 \mathrm{~mL} / \mathrm{min}$ at $275 \mathrm{~nm}$. The method was found to provide good resolution of aceclofenac and aceclofenac impurity-B. System suitability was performed before method validation. Appropriate chromatogram is presented in Figure 3.

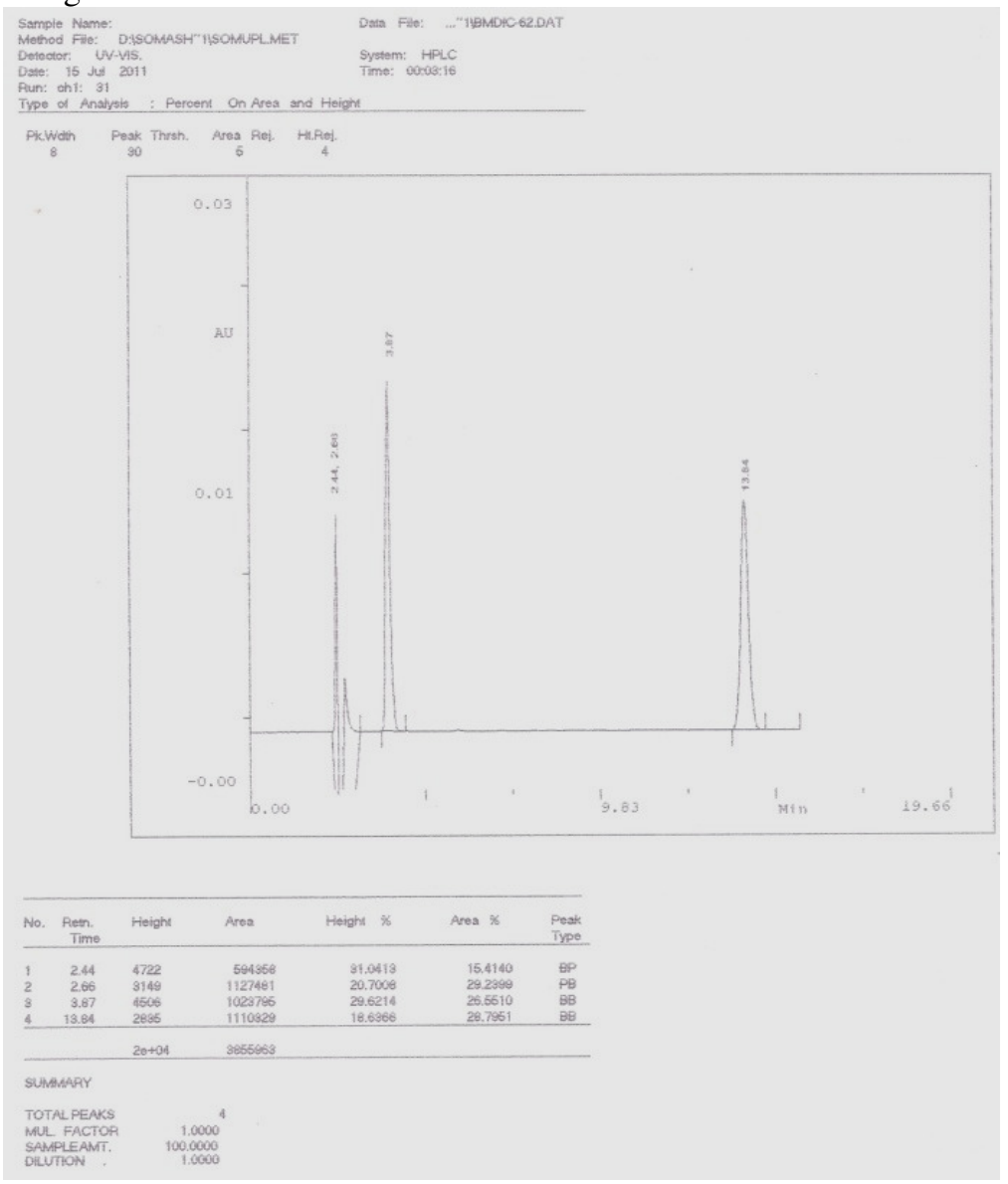

Figure 3. Resolution chromatogram of aceclofenac and aceclofenac impurity-B 
The method for estimation of aceclofenac and its impurity-B was validated as per ICH guidelines. The method was linear in the range of $1-25 \mu \mathrm{g} / \mathrm{mL}$ and $1-20 \mu / \mathrm{mL}$ for aceclofenac and aceclofenac impurity-B respectively. The Limit of detection was perfumed by instrumental visualization method and showed excellent sensitivity at $10 \mathrm{ng}$ level for both aceclofenac and aceclofenac impurity-B. The \%RSD values of concentration for method precision and peak area for system precision of six replicate injections of aceclofenac and aceclofenac impurity-B (Table 1) were found to be well within the acceptance criteria limit. Intra-day and inter-day precision (Table 2 and 3) were also performed at different time interval and different days, the results were found to be within the acceptance criteria. The accuracy study was carried out at $80 \%, 100 \%$ and $120 \%$ level using tablet formulation and recovery of aceclofenac impurity-B (Table 4) was calculated from regression equation and also assay of aceclofenac was calculated. The summarized validation parameters for aceclofenac and its impurities presented in Table 5.

Table 1. Method precision and system precision data of aceclofenac and aceclofenac impurity-B

\begin{tabular}{ccccc}
\hline \multirow{2}{*}{ Replicates } & \multicolumn{2}{c}{ Aceclofenac } & \multicolumn{2}{c}{ Impurity-B } \\
\cline { 2 - 5 } & Peak Area $^{*}$ & $\begin{array}{c}\text { Concentration } \\
\mu \mathrm{g} / \mathrm{mL}\end{array}$ & Peak Area $^{*}$ & $\begin{array}{c}\text { Concentration } \\
\mu \mathrm{g} / \mathrm{mL}\end{array}$ \\
\hline 1 & 1045271 & 5.28 & 1136640 & 5.22 \\
2 & 1054120 & 5.32 & 1152380 & 5.29 \\
3 & 1092704 & 5.52 & 1162275 & 5.34 \\
4 & 1074228 & 5.42 & 1159460 & 5.32 \\
5 & 1051729 & 5.31 & 1163777 & 5.34 \\
6 & 1040975 & 5.26 & 1159684 & 5.32 \\
Average & 1059837.83 & 5.35 & 1155702 & 5.31 \\
Standard & 19767.1835 & 0.10066756 & 10127.0368 & 0.04499625 \\
Deviation & 1.86 & 1.87 & 0.87626663 & 0.84721422 \\
\% RSD & \multicolumn{5}{c}{ Average of Six readings }
\end{tabular}

Table 2. Intra-day precision data of aceclofenac and aceclofenac impurity-B

\begin{tabular}{cccccc}
\hline & \multirow{2}{*}{$\begin{array}{c}\text { Time } \\
\text { Interval }\end{array}$} & \multicolumn{2}{c}{ Aceclofenac } & \multicolumn{2}{c}{ Impurity-B } \\
\cline { 3 - 6 } & $\mathrm{h}$ & Peak Area $^{*}$ & $\begin{array}{c}\text { Concentration } \\
\mu \mathrm{g} / \mathrm{mL}\end{array}$ & Peak Area & $\begin{array}{c}\text { Concentration } \\
\mu \mathrm{g} / \mathrm{mL}\end{array}$ \\
\hline 1 & 1 & 1045271 & 5.28 & 1136640 & 5.22 \\
2 & 2 & 1054120 & 5.32 & 1128262 & 5.18 \\
3 & 4 & 1074228 & 5.42 & 1127687 & 5.18 \\
4 & 6 & 1040975 & 5.26 & 1136043 & 5.22 \\
5 & 8 & 1023599 & 5.17 & 1111898 & 5.11 \\
6 & 12 & 1032586 & 5.21 & 1116374 & 5.13 \\
\multicolumn{2}{c}{ Average } & 1045129.83 & 5.28 & 1126150.67 & 1126150.67 \\
Standard Deviation & 17695.9516 & 0.09011948 & 10133.35 & 10133.35 \\
\multicolumn{2}{c}{$\%$ RSD } & 1.69 & 1.70 & 0.89982207 & 0.89982207 \\
\hline
\end{tabular}


Table 3. Inter-day precision data of aceclofenac and aceclofenac impurity-B

\begin{tabular}{cccccc}
\hline \multirow{2}{*}{ Replicates } & \multirow{2}{*}{$\begin{array}{c}\text { Day } \\
\text { Interval }\end{array}$} & \multicolumn{2}{c}{ Aceclofenac } & \multicolumn{2}{c}{ Impurity-B } \\
\cline { 3 - 6 } & Peak Area* & $\begin{array}{c}\text { Concentration } \\
\mu \mathrm{g} / \mathrm{mL}\end{array}$ & Peak Area & $\begin{array}{c}\text { Concentration } \\
\mu \mathrm{g} / \mathrm{mL}\end{array}$ \\
\hline 1 & 1 Day & 1045271 & 5.28 & 1136640 & 5.22 \\
2 & 2 Day & 1053440 & 5.32 & 1118315 & 5.14 \\
3 & 3 Day & 1079828 & 5.45 & 1159684 & 5.32 \\
\multicolumn{2}{c}{ Average } & 1059513 & 5.35 & 1138213 & 1138213 \\
\multicolumn{2}{c}{ Standard Deviation } & 18061.22 & 0.09198 & 20729.3099 & 20729.3099 \\
\multicolumn{2}{c}{$\%$ RSD } & 1.70 & 1.71 & 1.82 & 1.82 \\
\hline
\end{tabular}

${ }^{*}$ Average of six readings

Table 4. Recovery study data of aceclofenac and aceclofenac impurity-B

\begin{tabular}{|c|c|c|c|c|c|c|c|c|}
\hline $\begin{array}{l}\frac{0}{0} \\
\stackrel{0}{0} \\
1\end{array}$ & 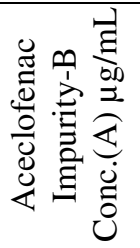 & 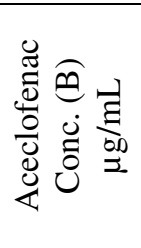 & 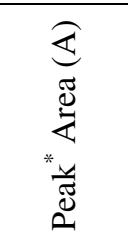 & 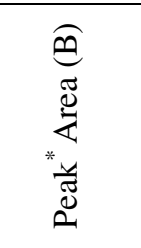 & 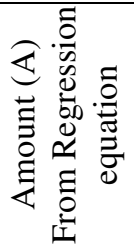 & 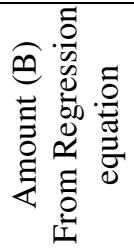 & 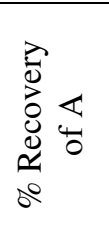 & 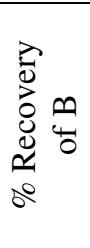 \\
\hline Level-I & 4 & 5 & 864840 & 998328 & 4.01 & 4.98 & 100.46 & 99.6 \\
\hline Level-II & 5 & 5 & 1108863 & 1028839 & 5.10 & 5.12 & 102.05 & 102.4 \\
\hline Level-III & 6 & 5 & 1284274 & 1012527 & 5.88 & 4.97 & 98.03 & 99.4 \\
\hline
\end{tabular}

Table 5. Validation parameter data aceclofenac and aceclofenac impurity-B

\begin{tabular}{|c|c|c|c|c|c|}
\hline $\begin{array}{l}\text { S. } \\
\text { No }\end{array}$ & \multicolumn{2}{|c|}{ Parameters } & \multirow{3}{*}{$\begin{array}{l}\begin{array}{c}\text { Data obtained } \\
\text { for aceclofenac }\end{array} \\
1-25 \mu \mathrm{g} / \mathrm{mL} \\
0.9991\end{array}$} & \multirow{3}{*}{$\begin{array}{l}\text { Data obtained for } \\
\begin{array}{c}\text { aceclofenac } \\
\text { impurity-B }\end{array} \\
1-20 \mu \mathrm{g} / \mathrm{mL} \\
0.9994\end{array}$} & \multirow{3}{*}{$\begin{array}{l}\begin{array}{c}\text { Acceptance } \\
\text { criteria }\end{array} \\
0.999\end{array}$} \\
\hline & Linearity & $\mu \mathrm{g} / \mathrm{mL}$ & & & \\
\hline & a) Regression & - & & & \\
\hline & Coefficient & & & & \multirow{4}{*}{$\begin{array}{l}\text { Not less } \\
\text { than } 99.7 \%\end{array}$} \\
\hline & b) Percentage & $\%$ & $99.91 \%$ & $99.99 \%$ & \\
\hline & curve fitting & - & & & \\
\hline & $\begin{array}{l}\text { c) Regression } \\
\text { Equation }\end{array}$ & $y=m x+c$ & $\begin{array}{l}y=196361 x+ \\
8026.6\end{array}$ & $\begin{array}{l}y=255064 x- \\
39631\end{array}$ & \\
\hline 2 & $\begin{array}{l}\text { Limit of } \\
\text { Detection (LOD) }\end{array}$ & $\begin{array}{l}\text { Visualization } \\
\text { methods }\end{array}$ & $0.1 \mu \mathrm{g} / \mathrm{mL}$ & $0.1 \mu \mathrm{g} / \mathrm{mL}$ & \\
\hline \multirow[t]{5}{*}{3} & Precision & & & & \multirow{5}{*}{$\begin{array}{l}\text { Not more } \\
\text { than } 2 \%\end{array}$} \\
\hline & $\begin{array}{l}\text { a) System } \\
\text { precision }\end{array}$ & $\%$ RSD & $1.87 \%$ & $0.87 \%$ & \\
\hline & b) Method & $\% \mathrm{RSD}$ & $1.86 \%$ & $0.84 \%$ & \\
\hline & $\begin{array}{l}\text { c) Intermediate } \\
\text { precision }\end{array}$ & $\begin{array}{l}\text { Inter day- } \\
\% \text { RSD }\end{array}$ & $1.70 \%$ & $0.89 \%$ & \\
\hline & & $\begin{array}{l}\text { Intra day- } \\
\% \text { RSD }\end{array}$ & $1.71 \%$ & $1.82 \%$ & \\
\hline
\end{tabular}




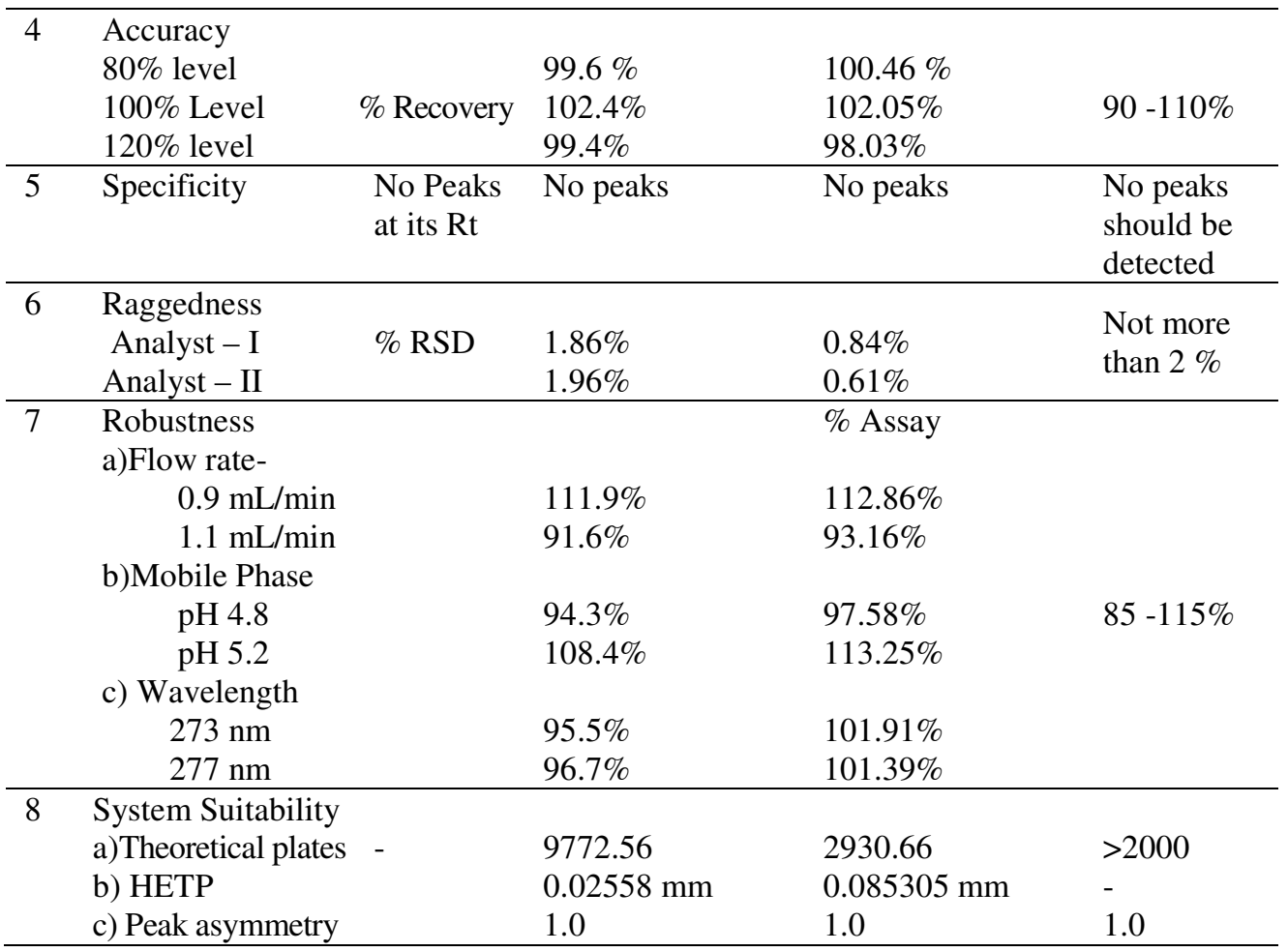

\section{Conclusion}

The proposed HPLC method for estimation of impurity-B in aceclofenac is analyzed in bulk drug as per ICH guidelines. The HPLC method was found to be linear, reproducible, sensitive, selective, and robust and can be used to separate simultaneously known aceclofenac impurity-B in aceclofenac drug substance. The method was evaluated through the method validation and proved to be selective, precise and accurate, so it can be used for separation, identification and simultaneous determination of aceclofenac and its impurity-B. Further work is being carried out to determine whether the method can be used or adopted for the detection and quantification of other known impurities in aceclofenac bulk drug.

\section{Acknowledgment}

Authors are thankful to Prof. B.G. Shivananda, Principal, Al-Ameen College of Pharmacy, Bangalore for providing necessary facilities. Authors also thankful to the Head of the department of Inorganic chemistry, Indian Institute of Science, Bangalore and the Director, Astra Zeneca India Pvt. Limited, Bangalore for spectral analysis.

\section{References}

1. The British pharmacopoeia, Her Majesty Stationary Office, 1998, 33-34.

2. The European pharmacopoeia, Supplement, 2000, 329-330.

3. Anthony C Moffat, David Osselton M, Brian Widdop, Clarke's Analysis of Drugs and Poisons K M, Varghese Company, Pharmaceutical Press, 2004, 3(2), 1363-1364.

4. Vergote V, Burvenich C, Van de Wiele C and De Spiegeleer B, J Pept Sci., 2009, 15, 697-710. 
5. Bari S B K B, Jaiswal Y S and Shikhedkar A A, Eurasian J Anal Chem., 2007, 2(1), 32-53.

6. De Spiegeleer B, Vergote V, Pezeshki A, Peremans K and Burvenich C, Anal Biochem., 2008, 376(2), 229-234.

7. Nicolas E C and Scholz T H, J Pharm Biomed Anal., 1998, 16(5), 813-824.

8. Roy J, AAPS Pharm Sci Tech., 2002, 3(2), 6.

9. ICH, Stability Testing of New Drug Substances and Products, Q1A (R2), 2003.

10. ICH Guidelines, Impurities in New Drug Products, Q3B (R1), 2006.

11. Kousy N M, J Pharm Biomed Anal., 1999, 20(1-2), 185-194.

12. Segun A Aderibigbe, Olajire A Adegoke, Olakunle S Idowu, Sefiu O Olaleye, Acta Poloniae Pharmaceutican Drug Res., 2012, 69(2), 203-211.

13. El-Saharty Y S, Refaat M, El-Khateeb S Z, Drug Dev Ind Pharm., 2002, 28(5), 571- 582.

14. Zawilla N H, Mohammad M Abdul Azim, El Kousy N M and El-Moghazy Aly S M, J Pharm Biomed Anal., 2002, 27(1-2), 243-251.

15. Lee H S, Jeong C K, Choi S J, Kim S B, Lee M H, Ko G I and Sohn D H, J Pharm Biomed Anal., 2000, 23(5), 775-781.

16. Prashant Musmade, Subramanian G and Srinivasan K K, Anal Chim Acta., 2007, 585(1), 103-109.

17. Hinz B, Auge D, Rau T, Rietbrock S, Brune $\mathrm{K}$ and Werner U, Biomed Chromatogr., 2003, 17(4), 268-275.

18. Raja R K, Sankar G G, Rao A L and Seshagiri Rao J V L N, Indian Drugs, 2005, 42(10), 693-695.

19. Jin Y, Chen H, Gu S and Zeng F, Chinese J Chromatogr., 2004, 22(3), 252-254.

20. Posac J R, Vazquez M D, Tascon M L, Acuna J.A, de la Fuente C, Velasco E and Sánchez-Batanero P, Talanta, 1995, 42(2), 293-304.

21. Wonku Kanga and Eun-Young Kim, J Pharm Biomed Anal., 2008, 46(3), 587-591.

22. Angelo Zinellu, Ciriaco Carru, Salvatore Sotgia, Emanuela Porqueddu, Paolo Enrico and Luca Deian, Eur J Pharm Sci., 2005, 24(4), 375-380.

23. Ashwini Ojha, Rajeshwari Rathod and Harish Padh, J Chrom B, 2009, 877(11-12), 1145-1148.

24. ICH Guidelines, Validation of Analytical procedures, Text and Methodology Q2(R1), 2005. 